\title{
Children Self Reporting Abuse and Neglect in the U.S.: A Multi-year Analysis
}

\author{
By John E. Kesner ${ }^{*} \&$ Robert D. Latzman ${ }^{ \pm}$
}

Child maltreatment represents a critical risk factor in the well-being of children around the world. There are a wide range of adverse outcomes associated with child maltreatment, both short and long term. Negative outcomes related to the child's physical and mental health as well as potential future psychiatric and criminal problems have been found. In the U.S. child protective services (CPS) are agencies whose sole mission is to both protect children and identify and hold accountable those who maltreat them. Each year, millions of reports of maltreatment are made to CPS. A fraction of these reports are made by the alleged victims of child maltreatment. The purpose of the current study was to describe reports made by the alleged victim of child maltreatment and to compare these reports to reports made by other adult reporters. More girls than boys made selfreports of alleged maltreatment to CPS. The average age of the self-reporter was older than the children involved in reports made by adult reporters. More African American and fewer White and Hispanic children selfreported alleged maltreatment compared to the other adult reporter groups. More self-reporters had a prior history of maltreatment compared to the other two adult reporter groups. Once CPS began the investigation, it took on average one day longer to make a finding for self-reports compared to reports made by mandated reporters. Results are discussed in terms of specific factors associated with self-reporters, public policy as well as cultural, racial and ethnic influences on the reporting of child maltreatment.

Keywords: child welfare, self-report, child maltreatment, child protective services.

\section{Introduction}

Child maltreatment is major risk factor for children's well-being in the United States and around the world. Child maltreatment is associated with a wide range of negative outcomes for both short-and long-term health, as well as psychiatric and criminal problems for the victim (Perry 2012, Felitti \& Anda 2009, Messman-

\footnotetext{
*Associate Professor, Georgia State University, USA.

${ }^{ \pm}$Associate Professor, Georgia State University, USA

1"The National Child Abuse and Neglect Data System (NCANDS) Child File data was provided by the National Data Archive on Child Abuse and Neglect at Cornell University, and have been used with permission. The data were originally collected under the auspices of the Children's Bureau, U.S. Department of Health and Human Services. The collector of the original data, the funder, NDACAN, Cornell University, and the agents or employees of these institutions bear no responsibility for the analyses or interpretations presented here. The information and opinions expressed reflect solely the opinions of the authors."
} 
Morre et al. 2010, Gold et al. 2011). Additionally, it is also associated with more acute outcomes, such as death. In fact, child maltreatment is the second leading cause of death in children in the U.S. (Felzen 2002, Ballesteros et al. 2018). Child protective services (CPS) in the U.S. are agencies designed to both protect children and identify and hold accountable individuals who maltreat them. They form a myriad of systems organized largely by each state with a common goal of protecting children from harm. Each year, out of all the millions of reports CPS receives, a fraction of them are made by the alleged victims of child maltreatment. For example, in 2010, one-half of one percent of the 3.5 million reports were made by the alleged victim (U.S. Department of Health and Human Services 2011). This figure, while seemingly inconsequential in comparison to the totality of child maltreatment reporting in the U.S., represents reports from the children for which child protective services was designed. That makes these reports of critical importance.

Traditionally, research in to the reporting of child maltreatment has focused on adult reporters, while research on reports made by alleged child victims has been virtually ignored. The few studies that have been carried out on self-reporting of maltreatment have generally focused on sexual abuse. These studies were usually retrospective in design or focused on clinical evidence (Haapasalo and Moilanen 2004, Aalsma et al. 2002). Given the scope of the child maltreatment problem in the U.S. and that self-reports come from the very people this system was designed to protect; more research is needed in this area.

\section{Children as Credible Sources}

Whenever children are the source of information related to an alleged criminal act, determining the credibility of their report becomes more complicated and raises some critical issues. Many view the child victim/witness as psychologically vulnerable, potentially suffering from posttraumatic stress, depression, anxiety or at the very least, having trust issues (Patton 2010). This vulnerability calls into question the credibility of their report and creates a dilemma for CPS as it must both investigate the alleged child maltreatment and protect the psychological health of the child. This is further complicated when the primary source of information about the alleged maltreatment is also the alleged victim.

From a legal standpoint, the credibility of a witness to criminal activity focuses on their perceived honesty and cognitive ability (Nunez et al. 2011). The age of the child is also a factor which must be weighed in determining the credibility of their report of alleged maltreatment. A younger child may be perceived as more honest, but at the same time, less credible due to their limited cognitive abilities. Conversely, older children may be perceived as more credible due to more advanced cognitive abilities, but potentially more dishonest (Buck and Warren 2009, Nikonova and Ogloff 2005, Nunez et al. 2011, Ross et al. 2003).

Studies into the credibility of child witnesses have utilized hypothetical scenarios and vignettes, surveys of children's attitudes or have focused on cases already in the legal system. But, understanding how the credibility of self-reports of child maltreatment at the initial stages of CPS's screening affects the 
investigation process is an essential first step. Before a maltreatment case reaches the courts, it must pass through several filters. The initial filter of CPS investigation is critical in determining if the report will be investigated. Examining extant reporting data from CPS agencies across the U.S. allows a glimpse into how CPS treats reports made by the alleged victim and whether there are systematic differences between these reports and those made by other adults.

Previous research has indicated that compared to reports made by adults, children's self-reports of maltreatment are less likely to be substantiated (Kesner 2007, Kesner et al. 2009). However, these studies were limited in scope, generally focusing on one year or two years of CPS data. Nonetheless, these studies raised important questions about how CPS views children's self-reported maltreatment. These limited analyses found differences related to the gender and race of the selfreporter and the substantiation rate of self-reports compared to reports by other adult reporters. It is essential to further examine these reports in more detail and for longer periods of time in order to observe trends in reporting practices.

\section{Current Study}

Using a population-based dataset, the purpose of this study was to describe reports made by the alleged child-victim of abuse and/or neglect and to compare these reports to those made by other adult reporters. Specifically, two research questions were addressed through data analysis. First, what demographic and other descriptive features distinguish child maltreatment reports made by the alleged victim? Specifically, the victim demographics, type of maltreatment alleged, whether the child was known to CPS from previous victimization and how often reports were substantiated. If the report was substantiated, reports were examined to determine the type of maltreatment substantiated and time taken by CPS to make a make a finding on the report. The second research question addressed how self-reports of maltreatment compared to other adult reporter groups on these same variables. The adult reporter group was broken down into two groups; reports made by adult professional reporters, adult non-professional reporters were compared to self-reports.

\section{Method}

\section{Sample}

The current study included population-based data from the National Child Abuse and Neglect Data System (NCANDS). Originally passed in 1974 and amended several times since, the Child Abuse and Prevention Treatment Act (CAPTA) required that the U.S. government establish a national database of child maltreatment reports. Each year states send data to NCANDS on the child maltreatment reports made to their respective child protective agencies (CPS). These data are then recoded and aggregated into a uniform database of child maltreatment reports from across the U.S. 
The sample used in the current study included 21,027,392 reports of child maltreatment in NCANDS from 2005-2010. Data from all 50 states, the District of Columbia and Puerto Rico comprised the final dataset with the exception of North Dakota and Oregon. North Dakota only contributed to NCANDS in 2005 and 2010, while Oregon contributed only in 2006. Because of this, a multi-year analysis was not possible with these two states, therefore they were excluded. With the exception of these two states, these data represent the sum total of child maltreatment reports in the U.S. for these years. Thus, rather than analyze a sample of reports, this study examined the characteristics of self-reports of child maltreatment in the U.S. for the entire population of reports during the years specified.

\section{Procedures}

The three groups of reporters discussed previously were created using the coding provided in the NCANDS datasets. The self-reporter group was comprised of reports where the source was coded as "alleged victim". The professional group included any report with a source coded as "social services", "medical", "mental health", "legal", "law enforcement", or "criminal justice" or "education personnel". The non-professional group was any report with a source coded as "foster care provider", "parent", "other relative", "friends/neighbors", or "anonymous reporter". Reports made by these groups were first described and then compared to each other, first on the characteristics of the reports of alleged maltreatment (reports received by CPS and selected for investigation) and then, if substantiated, the characteristics of the confirmed case of maltreatment.

To address the research objectives, two profiles for self-reports of maltreatment were generated. The first profile was comprised of reports of alleged maltreatment, included demographic characteristics of the alleged victim/reporter (i.e., age, gender, race, and ethnicity ${ }^{2}$ ). Additionally, this profile included the type of maltreatment reported, prior victimization status, rates of substantiation, and the time taken by CPS to begin the investigation and make a decision on the report. A second profile detailing information on the same variable listed above, but only with substantiated cases of self-reported maltreatment (the rate of substantiation variable was not included in this profile). Characteristics of these two profiles were then compared to the other two reporter groups (mandated and non-professional adults) on the same variables.

As discussed previously, these data represent the population of reports made in the U.S. between the years of 2005-2010. Thus, traditional significance testing was not utilized. Rather than drawing inferences based on significance testing of a sample, we chose to analyze the entire population. A determination of statistical significance is not necessary when the "sample" is for all intents and purposes, the population (Cowger 1984).

\footnotetext{
${ }^{2}$ Consistent with the U.S. Census, NCANDS treats race and ethnicity as separate variables.
} 


\section{Results}

\section{Self-Reporter Profile for Alleged Maltreatment Reports}

The average age of self-reporters was 12.6 years, with a majority of these reports coming from girls. Self-reports of alleged child maltreatment made by White children comprised the largest portion of this category (55\%), followed by African American children (29\%), American Indian or Alaska Native (1.7\%), Asian $(.8 \%)$ and Native Hawaiian $(.2 \%)$ children respectively. Fifteen percent of these reports were made by Hispanic children.

Seventy percent of self-reports made during the study period were made by children reporting for the first time, leaving $30 \%$ of self-reports made by children with a prior history of abuse and/or neglect. To determine the time taken by CPS to investigate and make a finding, the number of days from the beginning date of the investigation and the date a finding was made (substantiated or not) was calculated. On average, it took CPS an average 4 days to investigate and make a determination about reports of child maltreatment made by the alleged victim.

Child maltreatment reports made to CPS may involve more than one type of maltreatment. While NCANDS data do indicate when more than one type of maltreatment was included in a single report, not all reports involve multiple types of maltreatment and due to a significant amount of missing data from NCANDS related to additional types of maltreatment, these analyses focused on only the first type of maltreatment reported.

The majority of cases of alleged maltreatment reported by the victim involved neglect $(37 \%)$, followed by physical abuse $(26 \%)$ and reports of alleged sexual abuse was involved in $8 \%$ of the reports. NCANDS does collect data related to reports of psychological abuse, but as nearly one-half of these data were missing, this type of maltreatment was left out of the self-reporter profiles. Eighteen percent of self-reports were, upon investigation, substantiated by CPS.

\section{Profile for Self-Reporters (Substantiated Cases)}

The average age of the self-reporter in substantiated cases was 12.3 years. As was found in the profile of alleged maltreatment self-reports, more reports made by girls were substantiated more often than reports made by boys. Once again, the majority of reports substantiated by CPS were made by White children (57\%) followed by African American (24\%), American Indian (2.2\%), Asian (.8\%) and Native Hawaiian (.3\%) children respectively. Eighteen percent of substantiated cases involved Hispanic children. The majority of substantiated cases of maltreatment involved children who were not known to CPS (69\%), leaving nearly one-third who were prior victims.

The majority of substantiated cases involved neglect (42\%) then physical abuse $(21 \%)$ and finally sexual abuse $(15 \%)$. Missing data related to cases of psychological abuse did not allow it to be a part of the profile. 


\section{Comparisons on Reports of Alleged Maltreatment (3 Groups)}

Comparisons among the three reporter groups were made with variables associated with reports of alleged and substantiated cases of child maltreatment. Profiles, utilizing variables identical to those used in the self-reporter profile, were created for the two other reporter groups and compared to the profiles of the selfreporter on their reports. These comparisons revealed several differences.

The number of girls involved in self-reporting of alleged maltreatment was greater than the number of girls involved in reports made by the other two adult reporting groups. Similarly, self-reporters, on average, were older than children involved in reports by the other adult reporter groups. More African American and fewer White and Hispanic children self-reported alleged maltreatment compared to the other two adult reporter groups. More self-reporters had a prior history of maltreatment compared to children in the other two adult reporter groups. It took CPS an average of one day longer to make a determination in self-reports compared to reports made by the professional/mandated reporter group (see Table $1)$.

Table 1. Demographic Variables for Reports of Alleged Maltreatment from 3 Reporter Groups

\begin{tabular}{|l|c|c|c|}
\hline $\begin{array}{l}\text { Reports of Alleged } \\
\text { Maltreatment } \\
\text { Variable }\end{array}$ & Self-Reporter & $\begin{array}{c}\text { Mandated } \\
\text { Reporters }\end{array}$ & $\begin{array}{c}\text { Other Adult } \\
\text { Reporters }\end{array}$ \\
\hline Child Age & 12.6 & 8.5 & 8.2 \\
\hline Child is Male & $43 \%$ & $49 \%$ & $49 \%$ \\
\hline $\begin{array}{l}\text { Child is African } \\
\text { American }\end{array}$ & $29 \%$ & $25 \%$ & $23 \%$ \\
\hline Child is Asian & $.8 \%$ & $1.5 \%$ & $.8 \%$ \\
\hline $\begin{array}{l}\text { Child is American } \\
\text { Indian }\end{array}$ & $1.7 \%$ & $1.8 \%$ & $1.7 \%$ \\
\hline $\begin{array}{l}\text { Child is Native } \\
\text { Hawaiian }\end{array}$ & $.2 \%$ & $.4 \%$ & $.3 \%$ \\
\hline Child is White & $55 \%$ & $57 \%$ & $62 \%$ \\
\hline Child is Hispanic & $15 \%$ & $21 \%$ & $19 \%$ \\
\hline $\begin{array}{l}\text { Child is a Prior } \\
\text { Victim }\end{array}$ & $30 \%$ & $26 \%$ & $26 \%$ \\
\hline $\begin{array}{l}\text { Days: Investigation } \\
\text { start to conclusion }\end{array}$ & 4 & 3 & 4 \\
\hline
\end{tabular}

Self-reporters alleged more physical and sexual abuse compared to the other reporter groups. They also reported less neglect than the other adult reporter groups. Self-reports were substantiated less often than those of mandated reporters, but at the same rate as other adult reporters (see Table 2). 
Table 2. Reports of Alleged Maltreatment by Type of Maltreatment

\begin{tabular}{|l|c|c|c|}
\hline $\begin{array}{l}\text { Reports of Alleged } \\
\text { Maltreatment Variables }\end{array}$ & $\begin{array}{c}\text { Self- } \\
\text { Reporters }\end{array}$ & $\begin{array}{c}\text { Mandated } \\
\text { Reporters }\end{array}$ & $\begin{array}{c}\text { Other Adult } \\
\text { Reporters }\end{array}$ \\
\hline Physical Maltreatment Reported & $26 \%$ & $21 \%$ & $16 \%$ \\
\hline Neglect Reported & $37 \%$ & $45 \%$ & $61 \%$ \\
\hline Sexual Abuse Reported & $8 \%$ & $7 \%$ & $5 \%$ \\
\hline $\begin{array}{l}\text { Maltreatment Report } \\
\text { Substantiated }\end{array}$ & $18 \%$ & $31 \%$ & $18 \%$ \\
\hline
\end{tabular}

\section{Comparisons of Substantiated Cases}

Similar differences were found in comparisons between the three reporter groups when examining substantiated cases of maltreatment. Once again, older children were involved in self-reports of maltreatment compared to the other reporter groups. However, while the average age of children in self-reports was relatively constant, the age of children involved in reports made by the nonprofessional and professional reporter groups was almost 4 years younger. Substantiated cases of maltreatment were reported by mostly female children as compared to the children in reports made by the other adult reporter groups. Fewer African American children self-reported substantiated cases of maltreatment compared to the children involved in cases reported by mandated reporters, but more than cases reported by other adult reporters. The percentage of White children who self-reported substantiated cases of maltreatment was the same as in cases reported by mandated reporters, but less than the number involved in cases reported by other adult reporters. As was found with reports of alleged maltreatment, fewer Hispanic children self-reported substantiated cases of maltreatment compared to the other two adult reporter groups (see Table 3).

Table 3. Demographic Variables for Substantiated Cases of Maltreatment from 3 Reporter Groups

\begin{tabular}{|l|c|c|c|}
\hline $\begin{array}{l}\text { Substantiated Cases of } \\
\text { Maltreatment Variable }\end{array}$ & $\begin{array}{c}\text { Self- } \\
\text { Reporter }\end{array}$ & $\begin{array}{c}\text { Mandated } \\
\text { Reporters }\end{array}$ & $\begin{array}{c}\text { Other Adult } \\
\text { Reporters }\end{array}$ \\
\hline Child Age & 12.3 & 7.6 & 7.5 \\
\hline Child is Male & $40 \%$ & $49 \%$ & $49 \%$ \\
\hline Child is African American & $24 \%$ & $28 \%$ & $23 \%$ \\
\hline Child is Asian & $.7 \%$ & $1.4 \%$ & $.9 \%$ \\
\hline Child Is American Indian & $2.2 \%$ & $2 \%$ & $1.8 \%$ \\
\hline Child is Native Hawaiian & $.3 \%$ & $.5 \%$ & $.3 \%$ \\
\hline Child is White & $57 \%$ & $57 \%$ & $62 \%$ \\
\hline Child Is Hispanic & $18 \%$ & $22 \%$ & $21 \%$ \\
\hline Child is Prior Victim & $31 \%$ & $21 \%$ & $29 \%$ \\
\hline $\begin{array}{l}\text { Days: Investigation start to } \\
\text { conclusion }\end{array}$ & 4 & 2 & 3 \\
\hline
\end{tabular}

More self-reporters of substantiated cases had a prior history of maltreatment compared to cases reported by the other two adult reporter groups. When the report was substantiated, the number of days between the beginning of the 
investigation and its conclusion again, was longest for self-reporters. At four days, the number of days for self-reporters was twice that of mandated reporters and one day more than other adult reporters. Substantiated cases of maltreatment reported by the victim involved physical abuse more often than other adult reporters and neglect less often than those of the other two adult reporter groups. The percentage of substantiated self-reported sexual abuse cases nearly doubled from the percentage of self-reports of alleged sexual abuse while the percentages for mandated reporters and other adult reporters remained about the same (see Table 4).

Table 4. Substantiated Maltreatment Reports by Type of Maltreatment

\begin{tabular}{|l|c|c|c|}
\hline $\begin{array}{l}\text { Substantiated Maltreatment } \\
\text { Variables }\end{array}$ & $\begin{array}{c}\text { Self- } \\
\text { Reporters }\end{array}$ & $\begin{array}{c}\text { Mandated } \\
\text { Reporters }\end{array}$ & $\begin{array}{c}\text { Other Adult } \\
\text { Reporters }\end{array}$ \\
\hline Physical Maltreatment & $21 \%$ & $26 \%$ & $11 \%$ \\
\hline Neglect & $43 \%$ & $56 \%$ & $68 \%$ \\
\hline Sexual Abuse & $15 \%$ & $8 \%$ & $6 \%$ \\
\hline
\end{tabular}

\section{Discussion}

This population-based analysis of maltreatment reported by the alleged victim revealed critically important differences when compared to the reporting practices of other adult reporters. Given that children generally, are relatively powerless compared to adults (Bala et al. 2001), a child making a public accusation of abuse and/or neglect against a significant adult in their life is a significant event. However, the credibility of children as sources of information regarding these accusations is oftentimes suspect (Bala et al., 2001), and their reports may not be taken as seriously as the same report made by an adult. It is for these reasons, that a better understanding of self-reports of child maltreatment is critical

Results of the current study revealed that the self-reporter is more likely older and female, compared to children involved in reports by the other adult reporter groups. The findings that self-reporters are older than children involved in reports made by adult reporters is likely a reflection of the more advanced cognitive and verbal skills required for self-reporting maltreatment.

With regard to race and ethnicity, these results are generally consistent with previous research. For example, among reports of maltreatment by all reporter groups, African American children have been found to be overrepresented whereas Asian and White children are underrepresented when compared to their representation in the total population. Similarly, Hispanic children are slightly overrepresented in reports made by the two adult reporter groups. However, the proportion of Hispanic children self-reporting maltreatment was closer to their representation in the general population. These findings might suggest bias in the adult reporters in their reports of child maltreatment involving children of all races and ethnicities (over and underreporting respectively). The issue of reporter bias is irrelevant as the self-reporter and the alleged victim are one in the same. With the exception of Hispanic self-reporters, the overrepresentation and underrepresentation of certain racial groups in maltreatment reports suggests "visibility" 
in the social welfare system may be a factor (Wulzcyn 2009). African American family are generally overrepresented in the social welfare system (Hill 2006), thus a greater percentage of African American self-reporters may have more direct access to resources which may facilitate a self-report of maltreatment. Similarly, families involved with social services may be under greater scrutiny from these agencies where child maltreatment may be identified. Conversely, Asians and Whites are generally more affluent and less "visible" to social welfare agencies. Self-reporters in these groups may have a more difficult time making a self-report due to their unfamiliarity with or lack of access to social service agencies. Some studies have supported the idea that socioeconomic status is a factor in representation in the social welfare system. Currently, Asian-Americans have the highest median income of any racial or ethnic group in the U.S. and a U.S. Bureau of the Census study found that the number of Asian Americans involved in maltreatment reports increased when income was controlled (U.S. Census Bureau 2012).

The impact of factors such as parental attitudes, cultural values, poverty and immigrant status have been documented in previous research on the reporting of child maltreatment (Ashton 2002, Freisthler et al. 2007). Although previous research has found variations in parenting practices and cultural norms regarding parental authority in both Hispanic and Asian children (Chao 2000, Ferrari 2002, Okagaki and Bingham 2005), little research has investigated the role of these factors in the rate of self-report of child maltreatment. For example, Dixon et al. (2008) found significantly higher levels of respect for parental authority in African American and Hispanic girls evidenced significantly higher respect for parental authority than White girls. Further, compared to White, African American and Hispanic mothers showed higher levels of restrictive parenting behaviors. Variations in childrearing and discipline in particular, cultural values emphasizing respect for elders and a culture that places particular emphasis on the connectedness of family relationships may make it more difficult for children to self-report child abuse and neglect by a family member or member of the community (Fontes 2002, Lau et al. 2006). This may explain why fewer Hispanic and Asian Americans self-reported when compared to the other two adult reporter groups. However, this reasoning falls short in terms of explaining the selfreporting rate among African American children. As reported earlier, African American children show a higher level of respect for parental authority, yet they tend to self-report more maltreatment than White children. Thus, respect for family and community, may not be as much of a factor in the decision to selfreport. Clearly, there are other factors, yet unexplained, which contribute to the overrepresentation of African American children in reports by all reporter groups. It should also be noted that some believe that maltreatment in the U.S. is underreported (Giardino 2016). So, the self-reporting rate by all racial and ethnic groups may not reflect the actual incidence of child maltreatment. Issues such as respect for parental authority and a greater connectedness to the community may indeed be a factor in the decision of African American children to self-report. NCANDS data may reflect those cases where the maltreatment was so egregious that it brought them forward to report it. 
In addition to important differences found with regard to demographic characteristics of self-reporters, the substantiation rate of self-reported child maltreatment was quite low when compared to adult mandated reporters, but similar to the rate for other adult reporters. This was not unexpected as children's self-reports of maltreatment have not traditionally been substantiated at higher rates (Everson et al. 2008, Swahn et al. 2006).

As discussed previously, this may be due to the relatively low credibility given by authorities to self-reports of maltreatment (Everson et al. 2008). Given their naturally egocentric nature, children may still be developing notions of fairness and justice and may not be able to accurately evaluate the behaviors of adult caretakers. What children perceive as abuse and or neglect, may not meet the technical definition of maltreatment as set by CPS (Bala et al. 2001). This is not to suggest that self-reports of child maltreatment should not be investigated with the same rigor as those made by adults. It should be noted however, that reports made by non-professional reporters had a substantiation rate similar to self-reporters. So, the issues of credibility of a report may not be limited to self-reports made by children.

The finding that self-reporters had more substantiated cases of physical abuse compared to the other adult reporters, but not professional adult reporters is somewhat confusing. Of all the forms of child maltreatment, physical abuse is the least ambiguous. Visible evidence of physical abuse can leave little doubt that it occurred. The other types of maltreatment, often vaguely defined, are more difficult to assess and oftentimes more difficult for children to understand. Kantor and colleagues (2004) found that even with adjusting the questioning, younger children were less likely to reliably report neglect when compared to older children. Given this, it could be expected that self-reporters would have the highest percentage of these cases. The immediacy of the physical evidence in selfreporters should make investigation by CPS much more efficient. It may be possible that professional adult reporters, by nature of their work are better at collecting evidence that would support the physical evidence of maltreatment. This is clearly an area for future research.

The slightly longer time needed by CPS to investigate and make a finding in self-reports of maltreatment may be the result of difficulties associated with the reporter's age and alleged victim status. The reporter group with the shortest investigation time was the mandated reporter group. This may be a reflection of the fact that mandated reporters are typically individuals who regularly come into contact with children and, in turn, are likely better equipped to observe and draw conclusions related to suspected child maltreatment. Traditionally this group of reporters has a higher substantiation rate than other non-professional reporters (U.S. Department of Health and Human Services 2011). Further, self-reporters were more likely to be prior victims of maltreatment when compared to children involved in reports made by the other two adult reporter groups. This suggests that children who are prior victims of maltreatment may be more familiar with the child protection system, making them more likely to report.

It is important to note that a slightly greater percentage of reports made by self-reporters involved sexual abuse compared to non-professional adult reporters. 
This difference was much greater when looking at the percentage of substantiated cases involving sexual abuse involving self-reporters. The percentage of sexual abuse cases substantiated by CPS was almost twice the percentage for professional adult reporters and more than twice the percentage for other adult reporters. This suggests that efforts to bring sexual abuse to the forefront of public attention may be evidencing some success and that, at least with child sexual abuse, self-reports are being taken more seriously by CPS.

\section{Limitations and Future Directions}

First and foremost, NCANDS is an administrative dataset and is not ideally suited for research. Secondary analyses such as these reported here are limited by the variables used in the data collection system. Thus, the research questions which can be addressed are limited, as are the conclusions from any data analysis. The mapping process used by NCANDS to ensure uniformity of data across all states, although necessary for aggregating these data into a national dataset, may remove certain characteristics in each state's data. Additionally, due to variations in the maltreatment data each state collects and how these data are compiled, the issue of missing data further limits the national scope of NCANDS. Specifically, more detailed information about the victims, perpetrators, services provided and/or notifications to governmental agencies would help present a more complete picture of child maltreatment in the U.S. Finally, these results only reflect a certain period of time (2005-2010), thus the findings are limited in scope.

Future research should explore the differences found in this study to determine if they reflect real trends in the incidence of child maltreatment, child maltreatment reporting and the response by CPS. Preventing the incidence and reoccurrence of child maltreatment will only be successful with the cooperation of the public as well as the various public agencies associated with investigation. Further, the self-reporter of child maltreatment should be given equal consideration. As such, reports of maltreatment made by the alleged victim should be taken seriously by all concerned.

\section{References}

Aalsma MC, Zimet GD, Fortenberry D, Blythe M, Orr DP (2002) Reports of childhood sexual abuse by adolescents and young adults: Stability over time. Journal of Sex Research 39: 259 - 263.

Ashton V (2002) Worker judgments of seriousness about and reporting of suspected child maltreatment. Child Abuse \& Neglect 23(6): 539 - 548.

Bala N, Lee J, McNamara, E. (2001). Children as witnesses: Understanding their capacities, needs, and experiences. Journal of Social Distress and the Homeless 10: $41-68$.

Ballesteros MF, Williams DD, Mack KA, Simon TR, Sleet DA (2018) The Epidemiology of Unintentional and Violence-Related Injury Morbidity and Mortality among Children and Adolescents in the United States. International Journal of Environmental Research and Public Health 15(4): 616. doi:10.3390/ijerph 15040616. 
Buck JA, Warren AR (2009) Jurors and professionals in the legal system: What they know and what they should know about interviewing child witnesses. In The evaluation of child sexual abuse allegations: A comprehensive guide to assessment and testimony, K Keuhnle, M Connell (Eds), 501-530. Hoboken, NJ: John Wiley \& Sons Inc.

Chao RK (2000) The parenting of immigrant chinese and european american mothers: relations between parenting styles, socialization goals, and parental practices. Journal of Applied Developmental Psychology 21: 233 - 248.

Cowger CD (1984) Statistical Significance Tests: Scientific Ritualism or Scientific Method? Social Service Review 58(3): 358-372.

Dixon SV, Graber JA, Brooks-Gunn J (2008) The roles of respect for parental authority and parenting practices in parent-child conflict among african american, latino, and european american families. Journal of Family Psychology 22: 1 - 10.

Everson MD, Smith JB, Hussey JM, English D, Litrownik AJ, Dubowitz H (2008) Concordance between Adolescent Reports of Child Abuse and Child Protective Service Determinations in an At-Risk Sample of Young Adolescents. Child Development 13: 14 - 26.

Felitti VJ, Anda R (2009) The relationship of adverse childhood experiences to adult medical disease, psychiatric disorders, and sexual behavior: Implications for healthcare. In The hidden epidemic: The impact of early life trauma on health and disease, R Lanius, E Vermetten, C Pain (Eds).

Felzen JC (2002) Child Maltreatment 2002: Recognition, reporting and risk. Pediatrics International 44: 554 - 560.

Ferrari AM (2002) The impact of culture upon child rearing practices and definitions of maltreatment. Child Abuse and Neglect, 26: 793 - 813.

Fontes LA (2002) Child Discipline and Physical Abuse in Immigrant Latino Families: Reducing Violence and Misunderstandings. Journal of Counseling and Development 80: $31-40$.

Freisthler B, Bruce E, Needell B (2007) Understanding the geospatial relationship of neighborhood characteristics and rates of maltreatment for black, hispanic, and white children. Social Work 52: 7 - 16.

Giardino AP (2016) Child Maltreatment: Emerging Issues in Practice, Care and Prevention. Hauppauge. New York: Nova Science Publishers, Inc.

Gold J, Wolan Sullivan M, Lewis M (2011) The relation between abuse and violent delinquency: The conversion of shame to blame in juvenile offenders. Child Abuse \& Neglect 35(7): 459-467.

Haapasalo J, Moilanen J (2004) Official and self-reported childhood abuse and adult crime of young offenders. Criminal Justice and Behavior 31: 127 - 138.

Hill RP (2006) Synthesis of research on disproportionality in child welfare: An update, New York: Center for the Study of Social Policy.

Kantor GK, Holt MK, Mebert CJ, Straus MA, Drach KM, Ricci LR, ... Brown W (2004) Development and Preliminary Psychometric Properties of the Multidimensional Neglectful Behavior Scale--Child Report. Child Maltreatment 9(4): 409-428. https://doi-org.ezproxy.gsu.edu/10.1177/10775 59504269530.

Kesner J (2007) Self-reports of child maltreatment in the U.S.: A key social indicator. Social Indicators Research 83: 117 - 124. doi: 10.1007/s11205-006-9064-4.

Kesner JE, Bingham GE, Kwon K (2009) Child maltreatment in the United States: An examination of child reports and substantiation rates. International Journal of Children's Rights 17: 433-444.

Lau AS, Huang MM, Garland AF, McCabe KM, Yeh M, Hough RL (2006) Racial variation in self-labeled child abuse and associated internalizing symptoms among adolescents who are high risk. Child Maltreatment 11: 168 - 181. 
Messman-Morre T, Walsh K, DiLillo D (2010) Emotion dysregulation and risky sexual behavior in revictimization. Child Abuse \& Neglect 34(12): 967-976.

Nikonova O, Ogloff JRP (2005) Mock jurors' perceptions of child witnesses: The impact of judicial warning. Canadian Journal of Behavioural Science 37: 1-19.

Nunez NL, Kehn A, Wright DB (2011) When children are witness: The effects of context, age, and gender on adults' perceptions of credibility and honesty. Applied Cognitive Psychology 25: 460-468. Doi: 10.1002/acp.1713.

Okagaki L, Bingham GE (2005) Parents' social cognitions and "their parenting behaviors. In Ecological Perspective on Parenting, T Luster, L Okagaki (eds), 3 - 33. Hillsdale, NJ: Lawrence Erlbaum Associates.

Patton WW (2010) Viewing child witnesses through a child and adolescent psychiatric lens: How attorneys' ethical duties exacerbate children's psychopathology. Widener Law Review 16 (369): 256-288.

Perry B (2012) Supporting maltreated children: Countering the effects of neglect and abuse. Adoption Advocate. Retrieved from https://bit.ly/2HLiOQx.

Ross DF, Jurden FH, Lindsay RCL, Keeney JM (2003) Replications and limitations of a two-factor model of child witness credibility. Journal of Applied Social Psychology 33: 418-430.

Swahn MH, Whitaker, DJ, Pippen CB, Leeb RT, Teplin LA, Abram KM, McClelland GM (2006) Concordance between self-reported maltreatment and court records of abuse or neglect among high-risk youths. American Journal of Public Health 96: $1849-1853$.

U.S. Census Bureau (2012) Statistical Abstract of the United States: 2012. Retrieved 5 November 2013.

U.S. Department of Health and Human Services (2011). Child Maltreatment 2011, Washington DC: U.S. Government Printing Office.

Wulzcyn F (2009) Epidemiological perspectives on maltreatment prevention. Preventing Child Maltreatment 19(2): 39-66. 
